systems are tris(diketonate) coordination compounds of trivalent metals. This was noticed as early as 1926 when has been noted that the crystal structures of trivalent metal pentane-2,4-dionato complexes of various metals appear to be grouped in several isomorphous series [2]. If the metal atom is coordinated by asymmetrical diketonate, two different isomers (facial and meridial) are possible. Our work concentrated on compounds where trivalent metals are coordinated by 1-phenylbutane-1,3-dionato ligands which were studied by single crystal X-ray diffraction and thermal analysis. The meridial complexes of iron(III), manganese(III), chromium(III) were already reported to be isomorphous based on their powder diffraction patterns [3]. We have shown that thay crystallize in the monoclinic system, space group $P 2_{1} / c$. The only facial isomers which could be isolated where those of chromium(III) and cobalt(III) complexes. They were both found to crystallize in two pseudopolymorphic modifications. Pure compounds crystallize in the space group $P-1$ with two molecules in the asymmetric unit. The crystal structures of the chromium and cobalt compounds are almost identical. Under same crystallization conditions, both compounds can also crystallize as hydrates. The hydrates crystallize in the space group $R-3$ with 12 molecules per unit cell. The two symmetrically independent molecules in the structure differ in the mode of hydratation. As is the case with the triclinic modifications, the trigonal modifications of both chromium and cobalt compounds are almost perfectly isostructural

[1] A. Kálmán, L. Párkányi, G. Argay, Acta Cryst. (1993) B49, 1039.

[2] W. T. Astbury, Proc. Roy. Soc. (1926) 28, 313.

[3] R. C Fay, T. S. Piper, J. Am. Chem. Soc. (1962) 84, 2303.

\section{MS13 P08}

Naphthyridines as building blocks: the helix structure of 2-N-acetylamino-7-methyl-1,8-naphthyridine. Laura Torre-Fernández $^{\mathrm{a}}$, Santiago García-Granda ${ }^{\mathrm{a}}$, Shyamaprosad Goswami ${ }^{\mathrm{b}}$, ${ }^{a}$ Departamento de Química Física y Analítica, University of Oviedo, (Spain). ${ }^{b}$ Departament of Chemistry, Department of Chemistry, Deemed University, West Bengal (India).

E-mail: 1tf@fq.uniovi.es

Keywords: hydrogen bonding, supramolecular, Naphthyridines

Multiple hydrogen-bonded assemblies in biological systems are important for the formation of the DNA double helix [1], [2] and protein helical structures [3]. It is interesting to further explore the possibility of multiple hydrogen-bonding in naphthyridines stabilizing the catemers especially those giving rise to helical structures [4].

The 1,8-naphthyridine system functionalized at positions 2 and/or 7 are promising for supramolecular architectures although they are not often used. We report the crystal molecular structure including the supramolecular selfassembly of one of this naphthyridines, 2-N-acetylamino7-methyl-1,8-naphthyridine with helical structure formed by both helices of opposed chirality, P and M, this could lead to helix structures. Interestingly, the terminal points i.e. the amide proton $(\mathrm{N}-\mathrm{H})$ and ring nitrogen $(\mathrm{N} 3)$ take part in hydrogen bonding and a helical structure result for this compound. Non-classical hydrogen bond interactions are shown in between $\mathrm{N} 2 \cdots \mathrm{H} 1-\mathrm{C} 11$ and $\mathrm{N} 2 \cdots \mathrm{H} 01-\mathrm{C} 1$.
Other two normal type of hydrogen bonds are found between $\mathrm{N} 1-\mathrm{H} 2 \cdots \mathrm{N} 3$ and $\mathrm{N} 3 \cdots \mathrm{H} 2-\mathrm{N} 1$ which are the key bond in the formation of single helical structure. An interlayer interaction is found between the interaction of C5$\mathrm{H} 6 \cdots \mathrm{O} 1$

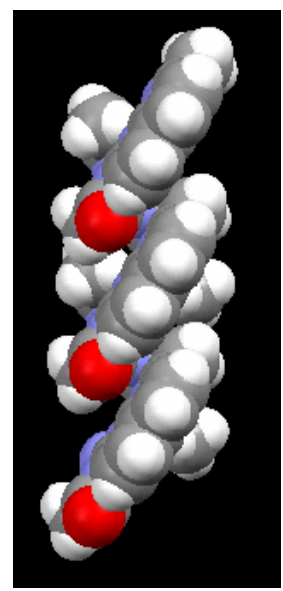

Fig.1. View illustrating the selfassembling hydrogen-bonded helices.

[1] Yoder, M. D.; Keen, N. T.; Jurnak, F. Science, 1993, 260, 1503

[2] Raetz. C. H. R.; Roderick, S. L. Science, 1995, 270, 997.

[3] Strobel, S.; Doucette-Stamm, L.; Riba, L.; Housman, D.; Dervan, P. Science, 1991, 254, 1639.

[4] Goswami, S. P.; Mukherjee, R.; Mukherjee, R; Jana, S.; Maity, A. C. A.; Adak, K. Molecules, 2005, 10, 929.

\section{MS13 P09}

Synthesis and Characterization of New Cerium and Chromium Compounds Barbara M. Casari ${ }^{\mathrm{a}}$, Vratislav Langer ${ }^{\mathrm{b}},{ }^{\mathrm{a}}$ Department of Chemistry, Inorganic Chemistry, Göteborg University, SE-412 96 Göteborg, Sweden. ${ }^{b}$ Environmental Inorganic Chemistry, Department of Chemical and Biological Engineering, Chalmers University of Technology, SE-41296 Göteborg, Sweden.

E-mail: casari@chem.gu.se

Keywords: Mixed valence, Cerium compounds, Chromium compounds

Syntheses and structural characterization of the compounds $\alpha-$ and $\beta-\mathrm{Ce}\left(\mathrm{SO}_{4}\right)_{2} \cdot 4 \mathrm{H}_{2} \mathrm{O}, \mathrm{Ce}_{2}\left(\mathrm{SO}_{4}\right)_{3} \cdot 4 \mathrm{H}_{2} \mathrm{O}$, $\beta-\mathrm{Ce}_{2}\left(\mathrm{SO}_{4}\right)_{3} \cdot 8 \mathrm{H}_{2} \mathrm{O}, \mathrm{K}_{5} \mathrm{Ce}_{2}\left(\mathrm{SO}_{4}\right)_{6} \cdot \mathrm{H}_{2} \mathrm{O}, \mathrm{K}_{2} \mathrm{Ce}\left(\mathrm{SO}_{4}\right)_{3} \cdot \mathrm{H}_{2} \mathrm{O}$, $\mathrm{K}_{5} \mathrm{Na}\left[\mathrm{Ce}_{2}\left(\mathrm{SO}_{4}\right)_{6}\right], \mathrm{CrCe}(\mathrm{III})_{7} \mathrm{Ce}(\mathrm{IV})_{6}\left(\mathrm{HSO}_{4}\right)_{6}\left(\mathrm{SO}_{4}\right)_{21} \cdot 75 \mathrm{H}_{2}$ $\mathrm{O} \mathrm{K}_{6}\left[\mathrm{Ce}\left(\mathrm{HSO}_{4}\right)_{2}\left(\mathrm{SO}_{4}\right)_{4}\right] \cdot \mathrm{H}_{2} \mathrm{O}, \mathrm{A}_{2}\left[\mathrm{CrCl}_{5}\left(\mathrm{H}_{2} \mathrm{O}\right)\right],\left(\mathrm{A}=\mathrm{NH}_{4}\right.$, $\mathrm{K}, \mathrm{Rb}, \mathrm{Cs}), \mathrm{NH}_{4} \mathrm{Cr}\left(\mathrm{CrO}_{4}\right)_{2}$ and $\mathrm{K}_{2} \mathrm{CrSO}_{7}$ are presented. The crystal structures have been determined from single crystal X-ray data and the thermal behaviours have been studied by TG, DSC and X-ray powder thermodiffractometry. The decomposition of $\mathrm{Ce}\left(\mathrm{SO}_{4}\right)_{2}$, into the final product $\mathrm{CeO}_{2}$, proceeds through intermediate $\mathrm{xCeO}_{2} \cdot \mathrm{yCe}\left(\mathrm{SO}_{4}\right)_{2}$ species. However, during the oxidative decomposition of $\mathrm{Ce}_{2}\left(\mathrm{SO}_{4}\right)_{3}$ into $\mathrm{CeO}_{2}$, small amount of $\mathrm{CeO}\left(\mathrm{SO}_{4}\right)$ is produced.

The four salts of the catalytically active $\left[\mathrm{CrCl}_{5}\left(\mathrm{H}_{2} \mathrm{O}\right)\right]^{2-}$ complex are prepared by different methods and reaction pathways are suggested. These compounds are composed of $\left[\mathrm{CrCl}_{5}\left(\mathrm{H}_{2} \mathrm{O}\right)\right]^{2-}$ units connected by $\mathrm{O}-\mathrm{H} \cdots . . \mathrm{Cl}$ hydrogen bonds and a counter ion framework. Further, for the first time, a mixed-valence chromium oxide has been synthesized starting from $\mathrm{CrO}_{3}$ in water solution. The reduction of the $\mathrm{Cr}(\mathrm{VI})$ into $\mathrm{Cr}(\mathrm{III})$ is presumably promoted by the oxidation of $\mathrm{Ce}(\mathrm{III})$. Among the mixed- 
valence chromates, $\mathrm{NH}_{4} \mathrm{Cr}\left(\mathrm{CrO}_{4}\right)_{2}$ constitutes a new structure type. The first known compound containing the $\mathrm{CrSO}_{7}^{2-}$ anion is described.

The first rare-earth sulfate containing more than one alkali element structurally characterized is $\mathrm{K}_{5} \mathrm{Na}\left[\mathrm{Ce}_{2}\left(\mathrm{SO}_{4}\right)_{6}\right]$. Its structure consists of pairs of edge sharing cerium polyhedra, interlinked by edge and corner sharing sulfate groups, forming layers connected by potassium ions. Also the acidic $\mathrm{K}_{6}\left[\mathrm{Ce}\left(\mathrm{HSO}_{4}\right)_{2}\left(\mathrm{SO}_{4}\right)_{4}\right] \cdot \mathrm{H}_{2} \mathrm{O}$ is unique and constitutes a new structure type since it contains rare-earth monomers, $\left[\mathrm{Ce}\left(\mathrm{HSO}_{4}\right)\left(\mathrm{SO}_{4}\right)_{4}\right]^{5-}$.

The existence of alterable oxidation states for the cerium ion may be a base for new attractive applications in the future. In the structure of $\mathrm{K}_{5} \mathrm{Ce}_{2}\left(\mathrm{SO}_{4}\right)_{6} \cdot \mathrm{H}_{2} \mathrm{O}$, there are pairs of edge sharing cerium polyhedra with one delocalized $f^{1}$ electron. The cerium polyhedra are linked through edge and corner sharing sulfate bridges thereby forming layers joined by potassium ions. The oxidation state of each cerium ion is 3.5. The structure of $\mathrm{CrCe}(\mathrm{III})_{7} \mathrm{Ce}(\mathrm{IV})_{6}\left(\mathrm{HSO}_{4}\right)_{6}\left(\mathrm{SO}_{4}\right)_{21} \cdot 75 \mathrm{H}_{2} \mathrm{O}$ differs significantly from previously known structures of mixedvalence cerium compounds. It extends to form layers through which there are large open channels, c.a $10 \AA$ in diameter.

\section{MS13 P10 \\ Complex Structures of Simple Molybdates. \\ Wieslaw Lasocha, ${ }^{\mathrm{a}, \mathrm{b}}$, Alicja Rafalska-Lasocha ${ }^{\mathrm{a}}$, Maciej Grzywa $^{\mathrm{b}}$, Bartlomiej Gawel ${ }^{\mathrm{a}}$, Wojciech Nitek ${ }^{\mathrm{a}},{ }^{a}$ Faculty of Chemistry Jagiellonian University, ${ }^{b}$ Institute of Catalysis \& Surface Chemistry PAS, Kraków, POLAND E-mail: lasocha@chemia.uj.edu.pl}

Keywords: crystal structure and properties, inorganic synthesis, catalysis

Octamolybdates are the most numerous, important and interesting group of molybdates. They are thoroughly investigated due to their vast applications in catalysis. Octamolybdates are also promising materials for optoelectronic applications. In this report we describe three new octamolybdates. Even though the conditions of their syntheses were very similar and quite simple, different from each other compounds were obtained. All of them are organoammonium octamolybdates, but their structures differ significantly. In $\mathbf{M o}_{8} \mathbf{O}_{26} \mathbf{C a ~ N}_{\mathbf{4}} \mathbf{C}_{\mathbf{1 0}} \mathbf{H}_{22}$ Ca (1), coordination polymeric structure exists, octamolybdate anions are connected by $\mathrm{Ca}^{2+}$ cations and create straight chains surrounded by organic cations. $\mathrm{Mo}_{8} \mathrm{O}_{26} \cdot \mathbf{2}\left(\mathrm{C}_{6} \mathrm{H}_{4}\left(\mathrm{NH}_{2}\right)_{2}\right) \cdot \mathbf{4}\left(\mathrm{C}_{6} \mathrm{H}_{4}\left(\mathrm{NH}_{2}\right)_{2}\right)$ belongs to the family of molybdates in which $\mathrm{Mo}^{+6}$ cation is directly bonded to $\mathrm{N}$ atoms. In $\mathrm{Mo}_{8} \mathrm{O}_{26} \cdot \mathbf{4}\left(\mathrm{C}_{10} \mathrm{H}_{7} \mathrm{NH}_{3}\right) \cdot \mathbf{4}\left(\mathrm{C}_{10} \mathrm{H}_{7} \mathrm{NH}_{2}\right) \cdot \mathbf{4} \mathrm{H}_{2} \mathrm{O}$ (3) $\mathrm{Mo}_{8} \mathrm{O}_{26}{ }^{4-}$ anions are separated by double organic layers consisted of 2-ammoniumnaphthalene cations, 2-aminenaphthalene molecules and molecules of water. The thickness of the layers is about $18 \AA$.

All compounds were synthesised for the first time in our laboratory. In addition to crystal structure studies, they were also characterised by IR spectroscopy and DSC investigations.

Crystallographic data for the investigated compounds:

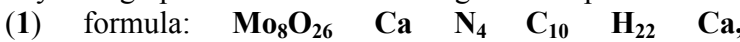
a,b,c, $\alpha \beta, \gamma=9.732(2) \mathrm{A}, 10.575(2), 11.686(2) \mathrm{A}, 65.34(2)^{\circ}$. 65.61(2) ${ }^{\circ}, 86.88(2)^{\circ}, \mathrm{V}=985.2(3) \mathrm{A}^{3}, \mathrm{SG}, \mathrm{P}-1$ (2) $\mathrm{Z}=2$.

(2) formula: $\mathrm{Mo}_{8} \mathrm{O}_{26} .2\left(\mathrm{C}_{6} \mathrm{H}_{4}\left(\mathrm{NH}_{2}\right)_{2}\right) \cdot \mathbf{4}\left(\mathrm{C}_{6} \mathrm{H}_{4}\left(\mathrm{NH}_{2}\right)_{2}\right)$ $.4 \mathbf{H}_{2} \mathbf{O}, \mathrm{a}, \mathrm{b}, \mathrm{c}, \alpha, \beta, \gamma=8.441(4) \AA, 12.121(4) \AA, 14.646(5) \AA$, $87.834(4)^{\mathrm{o}}, 78.148(4)^{\mathrm{o}}, 84.454(4)^{\mathrm{o}}, \mathrm{V}=1459.3 \AA^{3}, \mathrm{SG}=\mathrm{P}-1$ (2), $\mathrm{Z}=1$.

(3) formula: $\mathrm{Mo}_{8} \mathrm{O}_{26} \cdot \mathbf{4}\left(\mathrm{C}_{10} \mathrm{H}_{7} \mathbf{N H}_{3}\right) \cdot \mathbf{4}\left(\mathrm{C}_{10} \mathrm{H}_{7} \mathbf{N H}_{2}\right) \cdot \mathbf{4} \mathrm{H}_{2} \mathrm{O}$. $\mathrm{a}, \mathrm{b}, \mathrm{c}, \alpha, \beta, \gamma=10.184(5) \AA, 10.592(5) \AA, 22.737(7) \AA$, $78.675(5)^{\mathrm{s}}, 78.900(5)^{\mathrm{o}}, 65.427(5)^{\mathrm{o}}, \mathrm{V}=2170.1 \AA^{3}, \mathrm{SG}=\mathrm{P}-1$ (2), $\mathrm{Z}=1$.

\section{MS13 P11}

Synthesis, crystal structures and properties of metal

silicates Kwang-Hwa Lii, Department of Chemistry,

National Central University, Chungli, Taiwan.

E-mail: $\underline{\text { liikh@cc.ncu.edu.tw }}$

Keywords: silicate, lanthanide, uranium, synthesis, crystal structure

Recently much work has focused on the synthesis of transition metal silicates because of their rich structural chemistry and interesting physical and chemical properties. Most of these compounds were synthesized with alkali metal cations under hydrothermal conditions at 180-240 ${ }^{\circ} \mathrm{C}$. Our synthetic methods are 2-fold, namely high-temperature, high-pressure hydrothermal reactions at ca. $550-600{ }^{\circ} \mathrm{C}$ and $1000-2000$ bars with alkali metal counter cations and molten flux reactions at high temperature. We have synthesized a large number of new silicates of transition metals, main group elements, lanthanides, and uranium. For example, we reported the synthesis of $\mathrm{Rb}_{4}(\mathrm{NbO})_{2} \mathrm{Si}_{8} \mathrm{O}_{21}$ and its solid-state NMR spectra. The ${ }^{29} \mathrm{Si}$ MAS NMR spectrum shows multiplet patterns which arise from ${ }^{93} \mathrm{Nb}$ (spin-9/2)- ${ }^{29} \mathrm{Si} J$-coupling. This is the first example of two-bond $J$-coupling between a quadrupolar nucleus and a spin-1/2 nucleus in the solid state. The structure $\mathrm{Rb}_{3} \operatorname{In}\left(\mathrm{H}_{2} \mathrm{O}\right) \mathrm{Si}_{5} \mathrm{O}_{13}$ consists of 5membered rings of corner-sharing $\mathrm{SiO}_{4}$ tetrahedra connected via corner sharing to four adjacent 5 -membered rings to form a $3 \mathrm{D}$ silicate framework which belongs to the $\mathrm{CdSO}_{4}$ topological type. The first pentavalent-uranium silicate, $\mathrm{K}(\mathrm{UO}) \mathrm{Si}_{2} \mathrm{O}_{6}$, has also been synthesized. In this presentation I will report the syntheses, crystal structures, solid-state NMR spectroscopy, and luminescence properties of a number of new metal silicates.

\section{MS13 P12}

2-D and 3-D structures of Luminescent Zinc MetalOrganic Frameworks. Tatiana V. Timofeeva, ${ }^{a}$ Christina A. Bauer, ${ }^{\mathrm{b}}$ Mark D. Allendorf ${ }^{\mathrm{b}} \cdot{ }^{a}$ Department of Natural Sciences, New Mexico Highlands University, Las Vegas, NM 87701, USA; ${ }^{b}$ Sandia National Laboratories, Livermore, CA 94551, USA.

E-mail: tvtimofeeva@nmhu.edu

Applications of metal-organic frameworks (MOFs) depend on their structural characteristics such as pores size and availability of absorption. The preparation and characterization of two zinc MOFs based on a flexible and emissive linker molecule, stilbene, is described. Reaction of trans-4,4'-stilbene dicarboxylic acid and zinc nitrate in $\mathrm{N}, \mathrm{N}$-dimethylformamide (DMF) yielded under different conditions in dense 2-D network, 1, or porous 3-D framework structure, 2. This framework consists of two interpenetrating cubic lattices, each featuring basic zinc carboxylate vertices joined by trans-stilbene. Fragment of one of such lattices is depicted below. 